Check for updates

Cite this: Chem. Sci., 2019, 10, 9679

๑ All publication charges for this article have been paid for by the Royal Society of Chemistry

Received 17th July 2019

Accepted 17th August 2019

DOI: $10.1039 /$ c9sc03531a

rsc.li/chemical-science

\title{
Ligand-controlled diastereodivergent, enantio- and regioselective copper-catalyzed hydroxyalkylboration of 1,3-dienes with ketones $\uparrow$
}

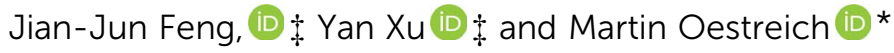

A copper-catalyzed three-component coupling of 1,3-dienes, bis(pinacolato)diboron, and ketones allows for the chemo-, regio-, diastereo- and enantioselective assembly of densely functionalized tertiary homoallylic alcohols. The relative configuration of the vicinal stereocenters is controlled by the chiral ligand employed. Subsequent transformations illustrate the versatility of these valuable chiral building blocks.

\section{Introduction}

The enantioselective synthesis of tertiary homoallylic alcohols ${ }^{1}$ continues to attract attention as these are highly useful intermediates in complex molecule synthesis and for medicinal chemistry. ${ }^{2}$ An established way to access that motif is by ketone allylation $^{3-7}$ where enantiofacial discrimination and low reactivity are the key challenges compared to aldehydes as electrophiles. ${ }^{8}$ Many methods are based on preformed allylmetal reagents. ${ }^{3-6}$ An alternative to these nucleophiles is their in situ formation by hydrometalation of 1,3 -dienes ${ }^{9,10}$ and allenes, ${ }^{10}$ and examples of transition-metal-catalyzed reductive couplings with ketones were recently achieved.$^{\mathbf{1 0 - 1 2}}$ A powerful variation of this approach is the borylmetalation of 1,3-dienes in the presence of a carbon electrophile. ${ }^{\mathbf{1 3 - 1 7}}$ These and related stereoselective borylative coupling reactions of other $\pi$-systems form a carbon-boron and a carbon-carbon bond in a single operation. ${ }^{\mathbf{1 3}}$ However, reactions involving ketones as electrophiles are scarce. ${ }^{\mathbf{1 4 , 1 7 a , d - g}}$ To the best of our knowledge, there are only three examples of the preparation of tertiary homoallylic alcohols by the borylative coupling strategy. Morken and coworkers reported a nickel-catalyzed three-component coupling of 1,3-dienes, bis(pinacolato)diboron, and ketones in racemic fashion (Scheme 1, top). ${ }^{\mathbf{1 4}}$ The reaction outcome was dependent on the substitution pattern of the 1,3-diene; $(E)$ penta-1,3-diene converted into 4,3-hydroxyalkylboration products while isoprene (one example) afforded the 4,1-hydroxyalkylboration product. Starting from allenes as the precursor of the allylic nucleophiles, Hoveyda and co-workers realized enantioselective borylative couplings with carbonyl

Institut für Chemie, Technische Universität Berlin, Strasse des 17. Juni 115, 10623 Berlin, Germany.E-mail: martin.oestreich@tu-berlin.de

$\dagger$ Electronic supplementary information (ESI) available. See DOI: 10.1039/c9sc03531a

\$ These authors contributed equally. compounds with syn selectivity but enantiocontrol was lower for ketones than for aldehydes (Scheme 1, middle). ${ }^{17 a}$ Low enantioselectivity was found by Tian and Tao in an

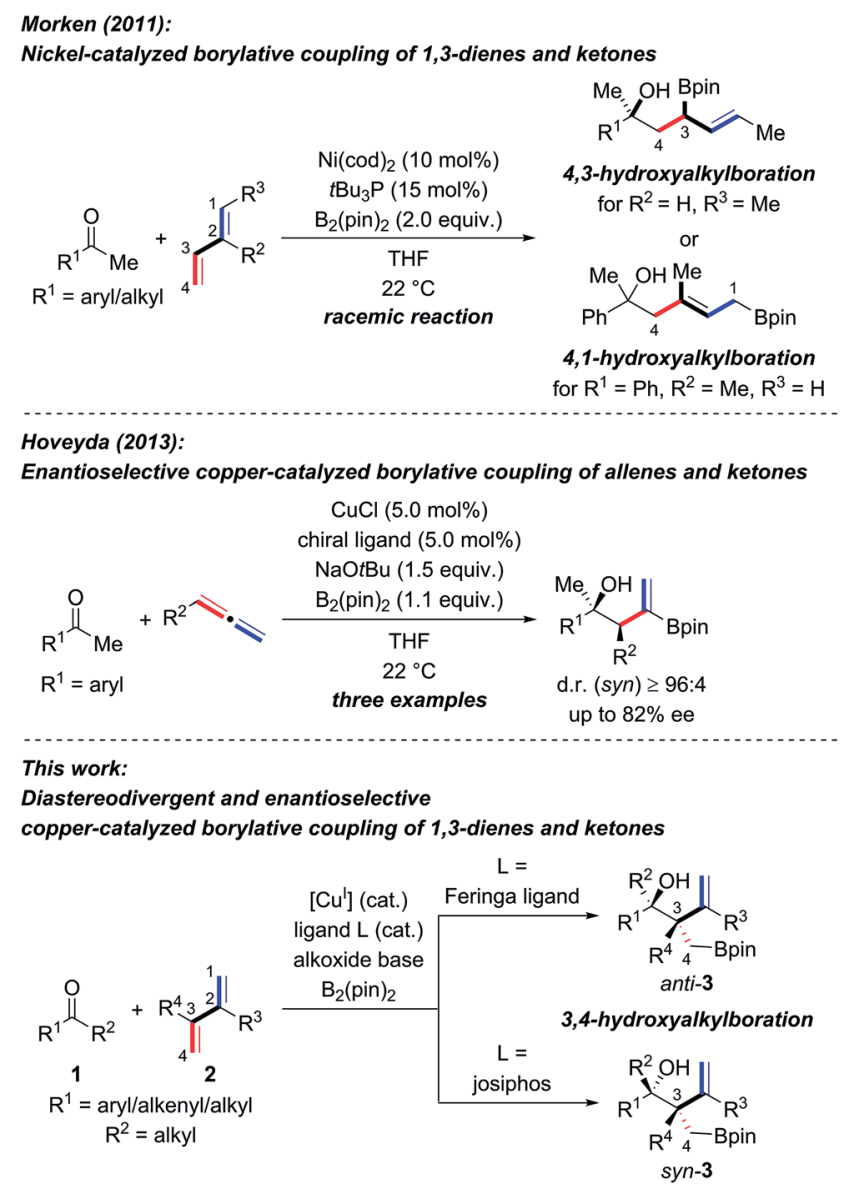

Scheme 1 Transition-metal-catalyzed intermolecular borylative coupling reactions of ketones for the construction of tertiary homoallylic alcohols. $\operatorname{cod}=$ cycloocta-1,5-diene, pin = pinacolato. 
intramolecular borylative cyclization of allenes tethered to cyclohexanediones (not shown). ${ }^{17 f}$ Hence, there is a demand for the development of new enantioselective borylative coupling reactions of $\pi$-systems and ketones to access chiral tertiary homoallylic alcohols. We disclose here such a copper-catalyzed three-component reaction with 1,3-dienes as the allylic coupling partner where the diastereoselectivity is determined by the ligand (Scheme 1, bottom)..$^{9 d, e}$

\section{Results and discussion}

For optimization, the three-component reaction of acetophenone (1a), isoprene (2a), and $\mathrm{B}_{2}(\mathrm{pin})_{2}$ was chosen as the model reaction. The ligand effects are summarized in Table 1 . In general, the reaction catalyzed by $\mathrm{CuCl}$ and phosphoramidite ligands afforded anti-4aa as the major diastereomer after oxidative degradation of the carbon-boron bond (see the ESI $\dagger$ for the complete set of data). ${ }^{18}$ As an example, anti-4aa formed in decent yield and with moderate stereoselectivity at room temperature in the presence of $\mathbf{C u C l} / \mathbf{L} 1$ and $\mathrm{NaO} t \mathrm{Bu}$ (entry $\mathbf{1}$ ). Further optimization of the copper source, solvent, and temperature led to a system which afforded the tertiary homoallylic alcohol anti-4aa as the major diastereomer in $94 \%$ NMR yield and with $90 \%$ ee (entries 2-4). In contrast to phosphoramidite ligands, bisphosphine ligands commonly used in copper catalysis such as L2 to L12 furnished syn-4aa as the major diastereomer at room temperature (entries 5-17), and commercially available josiphos derivative $\mathbf{L} \mathbf{9}$ was found to be optimal (entry 12). Lowering of reaction temperature from room temperature to $-20^{\circ} \mathrm{C}$ increased the enantiomeric excess and diastereoselectivity significantly but was detrimental to the yield (entry 13). Finally, high yield (98\% NMR yield) and stereoselectivity (93\% ee and d.r. $=87: 13$ in favor of syn) were restored in toluene/THF $8: 2$ with $5.0 \mathrm{~mol} \%$ CuOAc and 6.0 mol\% $\mathbf{L} \mathbf{9}$ as the catalyst-ligand combination (entry 14).

We next investigated the scope of ketones using $\mathbf{L 1}$ in the anti-selective procedure and $\mathbf{L 9}$ in the syn-selective setup (Conditions A and B, Scheme 2). Acetophenones with various substituents in the para position, including electron-donating groups (as in $\mathbf{1 b}, \mathbf{c}$ ) and halogens (as in 1d-f), exhibited high reactivity and stereoselectivity. A carboxyl group was compatible (as in $\mathbf{1 g}$ ), thus further emphasizing the functional-group tolerance of this reaction. $\mathbf{1 h}$ and $\mathbf{i}$ with meta substitution also gave satisfactory results. The reaction of ortho-methylsubstituted $\mathbf{1 j}$ was successful under Condition B and yielded syn-4ia with $98 \%$ ee (anti-4ja: $80 \%$ ee); conversely, poor stereoselectivity was obtained under Condition A. Pyridyl-substituted 11 reacted smoothly under Condition B and furnished syn-4la with good diastereoselectivity (d.r. $=90: 10)$ and enantioselectivity ( $90 \%$ ee); in turn, the reaction of $\mathbf{1 1}$ under Condition A produced anti-4la with a moderate ee value. Aside from aromatic methyl ketones, propiophenone (1m), which had not been compatible with Morken' ${ }^{14}$ and Hoveyda' ${ }^{17 a}$ catalytic system ( $c f$. Scheme 1), also furnished anti-4ma in excellent yield and good enantioselectivity with moderate diastereoselectivity under Condition A; B afforded the target compound in a similar
Table 1 Selected examples of the optimization of the borylative hydroxyalkylation of 1,3-dienes ${ }^{a}$

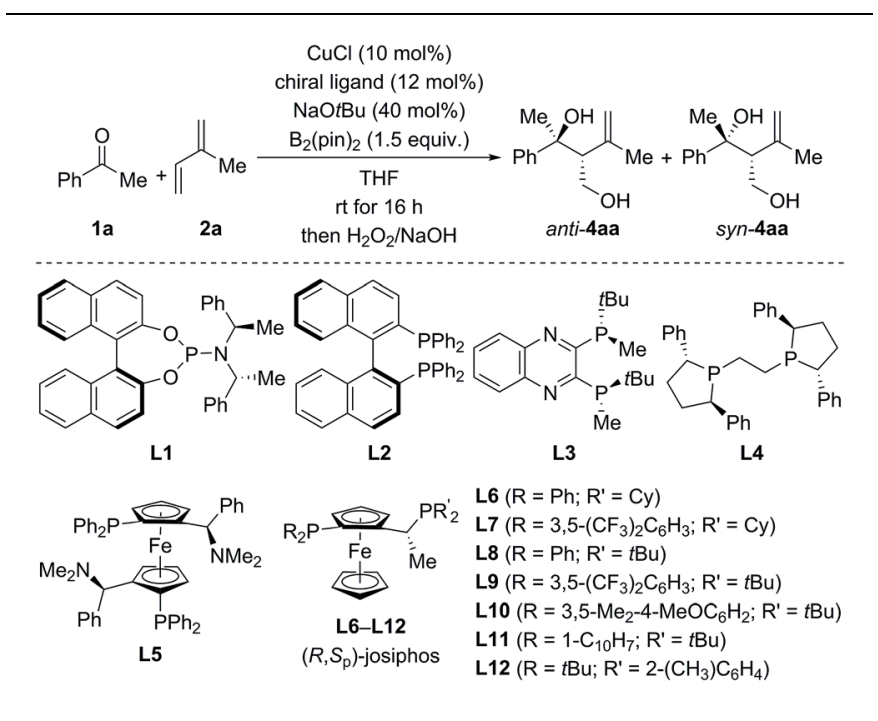

\begin{tabular}{|c|c|c|c|c|c|}
\hline \multirow[b]{2}{*}{ Entry } & \multirow[b]{2}{*}{ Ligand } & \multirow[b]{2}{*}{ Yield $^{b}(\%)$} & \multirow[b]{2}{*}{ d.r. (anti : syn) } & \multicolumn{2}{|l|}{$\mathrm{ee}^{c}(\%)$} \\
\hline & & & & anti-4aa & syn-4aa \\
\hline 1 & L1 & 53 & $71: 29$ & 60 & 21 \\
\hline $2^{d}$ & L1 & 88 & $66: 34$ & 64 & 10 \\
\hline $3^{d, e}$ & L1 & 96 & $68: 32$ & 68 & 30 \\
\hline $4^{d, e_{f} f}$ & L1 & 94 & $80: 20$ & 90 & 64 \\
\hline 5 & L2 & 75 & $42: 58$ & 43 & $32^{g}$ \\
\hline 6 & $\mathbf{L 3}$ & 92 & $35: 65$ & 6 & 35 \\
\hline 7 & $\mathbf{L 4}$ & 93 & $28: 72$ & $35^{g}$ & $32^{g}$ \\
\hline $8^{e}$ & L5 & 84 & $44: 56$ & 13 & 22 \\
\hline 9 & L6 & 45 & $23: 77$ & $22^{g}$ & 61 \\
\hline 10 & L7 & 98 & $23: 77$ & $13^{g}$ & 80 \\
\hline 11 & L8 & 80 & $22: 78$ & $72^{g}$ & 88 \\
\hline 12 & L9 & 98 & $23: 77$ & $74^{g}$ & 88 \\
\hline $13^{h}$ & L9 & 61 & $15: 85$ & $79^{g}$ & 94 \\
\hline $14^{h, i}$ & L9 & 98 & $13: 87$ & $71^{g}$ & 93 \\
\hline 15 & L10 & 65 & $28: 72$ & $71^{g}$ & 87 \\
\hline 16 & L11 & 37 & $47: 53$ & 0 & 37 \\
\hline 17 & L12 & 29 & $49: 51$ & - & - \\
\hline
\end{tabular}

${ }^{a}$ Unless otherwise noted, the reactions were performed with $\mathbf{1 a}(0.2$ $\mathrm{mmol})$, 2a $(1 \mathrm{mmol})$, and $\mathrm{B}_{2}(\mathrm{pin})_{2}(0.3 \mathrm{mmol})$ in THF $(2 \mathrm{~mL})$. ${ }^{b}$ Combined NMR yield determined by ${ }^{1} \mathrm{H}$ NMR spectroscopy with $\mathrm{CH}_{2} \mathrm{Br}_{2}$ as an internal standard. ${ }^{c}$ Determined by HPLC analysis on chiral stationary phases. ${ }^{d}$ CuOAc instead of CuCl. ${ }^{e}$ Toluene instead of THF. ${ }^{f}$ Run at $-30{ }^{\circ} \mathrm{C} .{ }^{g}$ The other enantiomer was obtained. ${ }^{h}$ Run at $-20{ }^{\circ} \mathrm{C}$. ${ }^{i} 0.4 \mathrm{mmol}$ scale, $5.0 \mathrm{~mol} \% \mathrm{CuOAc}$ and $6.0 \mathrm{~mol} \% \mathrm{~L} 9$ were used and toluene/THF $8: 2$ instead of THF.

yield yet with a high diastereomeric ratio and a markedly diminished ee value. Interestingly, $\alpha, \beta$-unsaturated ketone 1n reacted regioselectively (1,2- over 1,4 -addition) with good to excellent diastereoselectivity; syn-4na was the major product under both Condition A and B. Moreover, dialkyl ketone 10 converted into the corresponding products anti- and syn-4oa under A and B but with low diastereoselectivity likely due to the little steric differentiation between the methyl and methylene groups attached to the carbonyl carbon atom.

We then examined the scope of 1,3-dienes (Scheme 3). Isoprene (2a) could be replaced by buta-1,3-diene (2b), 


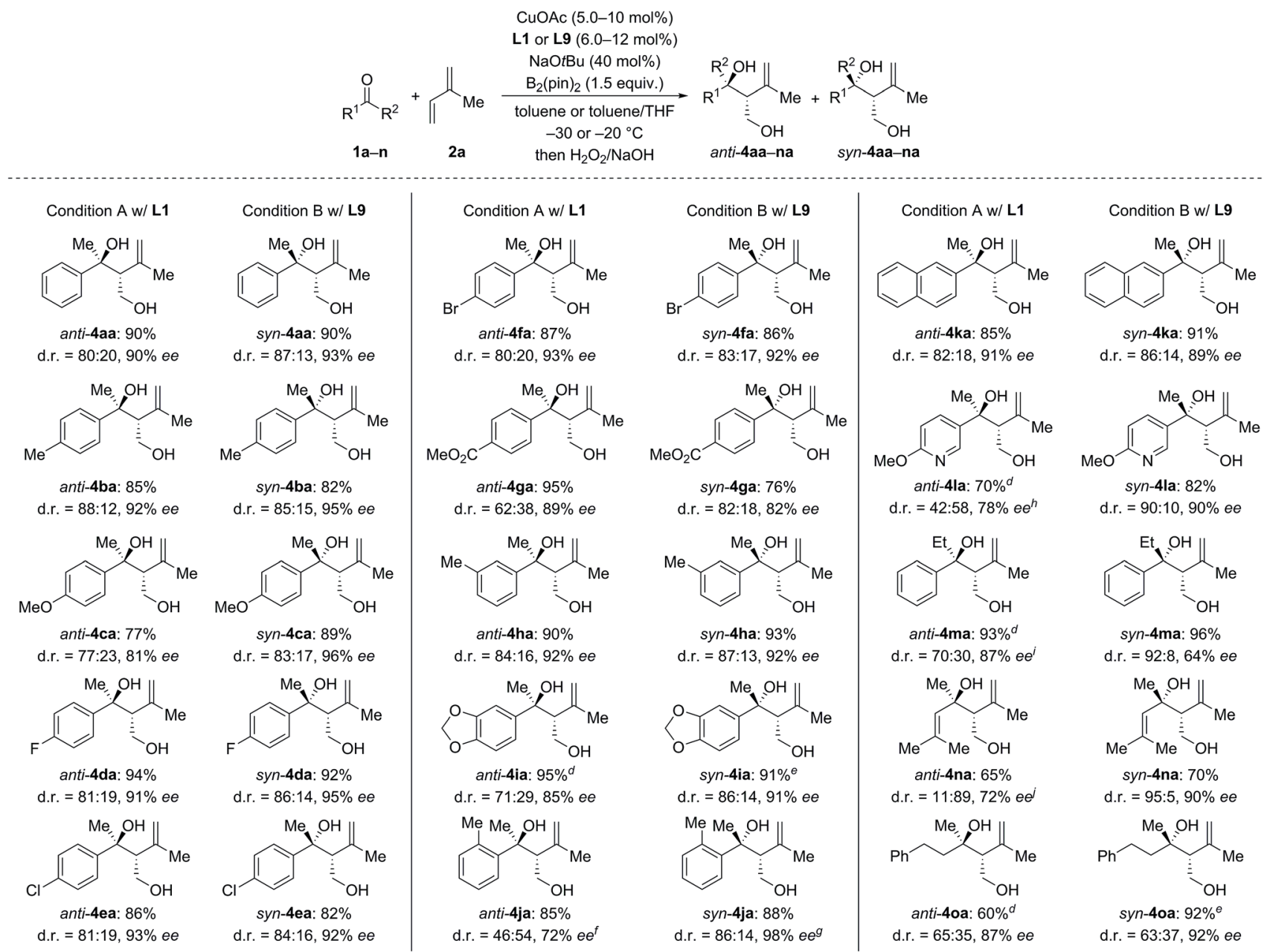

Scheme 2 Scope I: variation the ketone. ${ }^{a-c}$ a Condition A: CuOAc (10 mol\%), L1 (12 mol\%), NaOtBu (40 mol\%), ketone 1 (0.20 mmol), isoprene $(2 \mathrm{a}, 1.0 \mathrm{mmol})$, and $\mathrm{B}_{2}(\mathrm{pin})_{2}\left(1.5\right.$ equiv.) in toluene $(2 \mathrm{~mL})$ at $-30{ }^{\circ} \mathrm{C}$. Condition B: CuOAc $(5.0 \mathrm{~mol} \%), \mathrm{L} 9(6.0 \mathrm{~mol} \%), \mathrm{NaOtBu}(40 \mathrm{~mol} \%), \mathrm{ketone} 1$ $(0.40 \mathrm{mmol})$, isoprene $(2 \mathrm{a}, 2.0 \mathrm{mmol})$, and $\mathrm{B}_{2}(\text { pin })_{2}\left(1.5\right.$ equiv.) in toluene/THF $-8: 2(3.5 \mathrm{~mL})$ at $-20^{\circ} \mathrm{C}$. ${ }^{b}$ Yields are combined isolated material; diastereomers are usually separable by flash chromatography on silica gel. ${ }^{\mathrm{C}}$ The enantiomeric excess of the major diastereomer was determined by HPLC analysis on chiral stationary phases. ${ }^{\mathrm{d}} \mathrm{CuOAc}(15 \mathrm{~mol} \%)$ and L1 (18 mol\%) were used. ${ }^{\circ} \mathrm{CuOAc}(10 \mathrm{~mol} \%)$ and L9 (12 mol\%) were used.

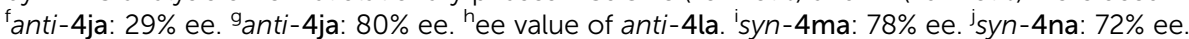

myrcene (2c), its functionalized derivative 2d, and 2,3dimethylbuta-1,3-diene (2e). Yields were generally good but stereoselectivities ranged from poor to good under Condition A. In contrast, good to excellent stereoselectivities were observed for these 1,3-dienes under Condition B, e.g., d.r. $=$ $96: 4$ and $92 \%$ ee for $1 \mathbf{n} \rightarrow$ syn-4nb and d.r. $=93: 7$ and $91 \%$ ee for $\mathbf{1 a} \rightarrow$ syn-4ad. In the case of 2 -aryl-substituted 1,3-diene 1f, diastereodivergency was not achieved. Subjecting 1f to Condition A afforded syn-4af in low yield as a single syn-isomer (not shown). However, applying Condition B at $-5{ }^{\circ} \mathrm{C}$ significantly improved the yield and furnished the syn-4af with d.r. > $98: 2$ and $85 \%$ ee.

To explore synthetic transformations of these tertiary homoallylic alcohols (Scheme 4), a scale-up synthesis of syn4aa $(1.0 \mathrm{mmol})$ under Condition B was done without any loss in efficiency and selectivity (see the ESI $\dagger$ ). The primary alkyl borane generated by the multicomponent reaction was subjected to a Suzuki-Miyaura coupling to afford $\operatorname{syn}-5$ in $83 \%$ yield (Scheme 4 , top). The versatility of the diol products $\mathbf{4}$ is illustrated for several transformations (Scheme 4, bottom). The 1,1-disubstituted double bond in anti-4ha was hydrogenated over $\mathrm{Pd} / \mathrm{C}$ to produce anti-6 in $87 \%$ yield. The hydroxy group in syn-4aa was replaced by an azide group through an $\mathrm{S}_{\mathrm{N}} 2$ reaction of an intermediate mesylate with $\mathrm{NaN}_{3}(\operatorname{syn}-\mathbf{4 a a}$ $\rightarrow$ syn-7). Pyran syn-8 was synthesized from syn-4ab by sequential alcohol allylation and ring-closing metathesis. Of note, a chemoselective tosylation of the primary alcohol in syn4aa followed by a 4-exo-tet ring closure allowed for the construction of enantioenriched, trisubstituted oxetane trans9 in $86 \%$ yield.

\section{Conclusion}

In summary, we have developed an efficient copper-catalyzed diastereodivergent and enantioselective borylative coupling of 1,3-dienes and ketones. Using a Feringa-type ligand L1, the 


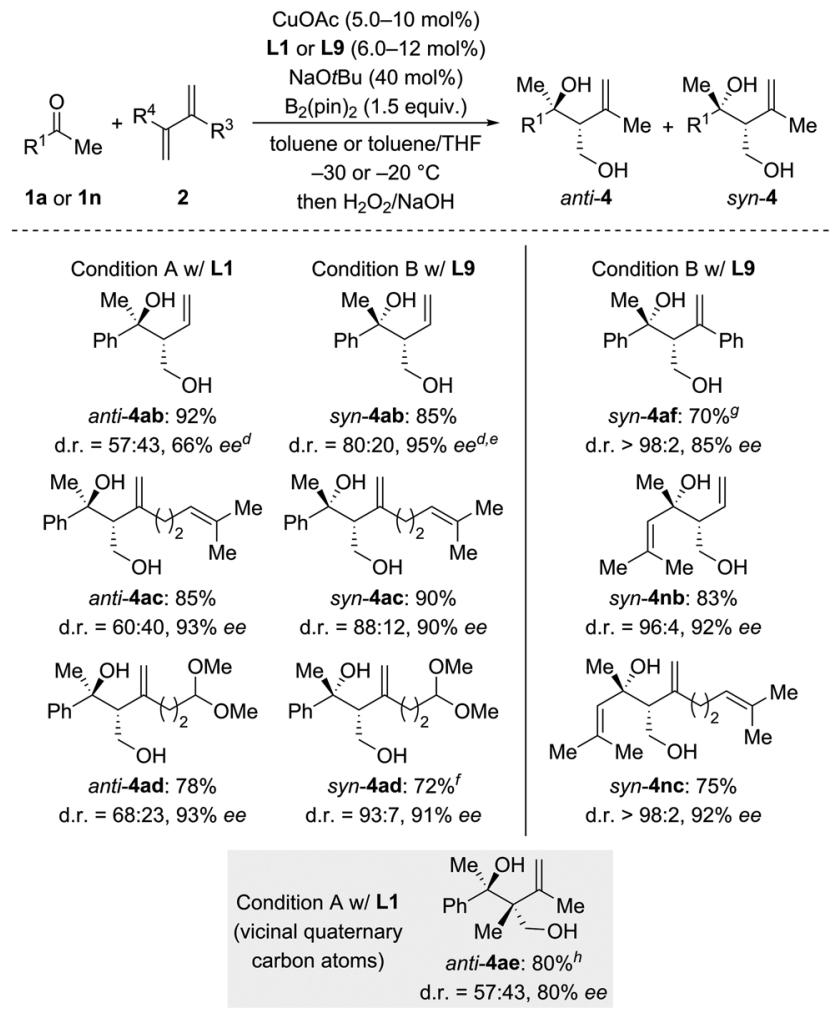

Scheme 3 Scope II: variation of the 1,3-diene. ${ }^{a-c}$ For footnotes a-c, see Scheme 2. ${ }^{\mathrm{d}}$ The absolute configuration was assigned by chemical correlation after separation of the diastereomers by flash chromatography on silica gel (see the ESI + ). ${ }^{e}$ anti-4ab: $84 \%$ ee. ${ }^{f} \mathrm{CuOAc}$ (8.0 mol\%) and L9 (10 mol\%) were used. ${ }^{9} \mathrm{Run}$ at $-5{ }^{\circ} \mathrm{C}$ with $\mathrm{CuOAc}$ (10 mol\%), L9 (12 mol\%), NaOtBu (50 mol\%), and $\mathrm{B}_{2}$ (pin) 2 (2.0 equiv.). ${ }^{\mathrm{h} C u O A c}(15 \mathrm{~mol} \%)$ and L1 (18 mol\%) were used.

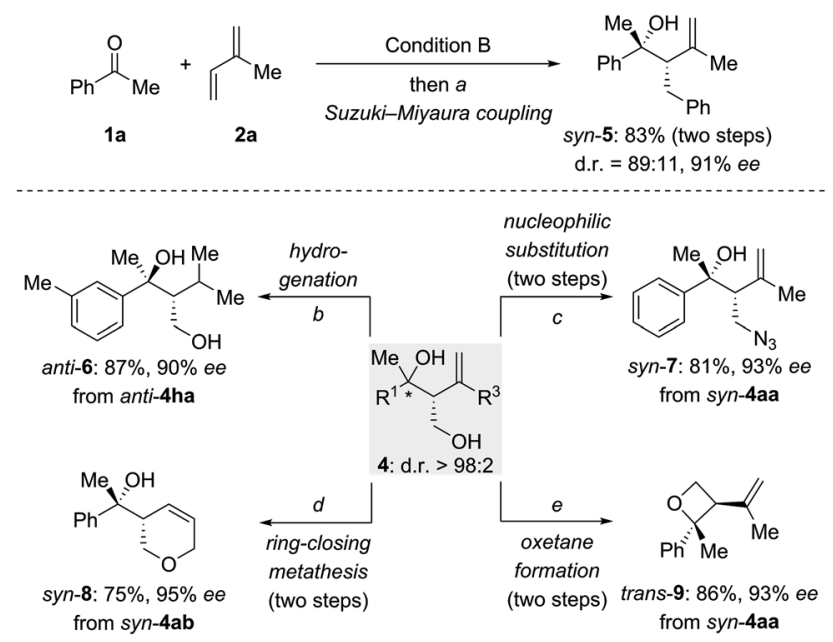

Scheme 4 Tertiary homoallylic alcohols as versatile building blocks. (a) $\mathrm{PhBr}$ (1.8 equiv.), $\mathrm{Pd}(\mathrm{OAc})_{2}$ (5.0 mol\%), RuPhos (10 mol\%), KOtBu (3.0 equiv.), toluene/ $\mathrm{H}_{2} \mathrm{O}(10 / 1), 80{ }^{\circ} \mathrm{C}, 24 \mathrm{~h}$; (b) $\mathrm{Pd} / \mathrm{C}(10 \%), \mathrm{H}_{2}$ (1 atm), $\mathrm{MeOH}, \mathrm{rt}, 26 \mathrm{~h}$; (c) (i) $\mathrm{MsCl}$ (1.5 equiv.), $\mathrm{Et}_{3} \mathrm{~N}$ (1.5 equiv.), $\mathrm{CH}_{2} \mathrm{Cl}_{2}, \mathrm{O}^{\circ} \mathrm{C}$ to rt, 50 min; (ii) $\mathrm{NaN}_{3}$ (2.0 equiv.), DMF/ $\mathrm{H}_{2} \mathrm{O}$ (10/1), $80^{\circ} \mathrm{C}, 12 \mathrm{~h}$; (d) (i) $\mathrm{NaH}$ (2.0 equiv.), allyl bromide (1.1 equiv.), THF, $0^{\circ} \mathrm{C}$ to rt, $14 \mathrm{~h}$; (ii) HoveydaGrubbs II (5.0 mol\%), $\mathrm{CH}_{2} \mathrm{Cl}_{2}, \Delta, 12 \mathrm{~h}$; (e) (i) $\mathrm{TsCl}$ (2.4 equiv.), pyridine, $0{ }^{\circ} \mathrm{C}$ to rt, $24 \mathrm{~h}$; (ii) $n$ BuLi (1.1 equiv.), $-25{ }^{\circ} \mathrm{C}$ to $\mathrm{rt}, 15 \mathrm{~h}$. Ms = methanesulfonyl. reaction yielded anti-configured tertiary homoallylic alcohols while a switch to josiphos ligand L9 resulted in syn selectivity (see the ESI $\dagger$ for a discussion of the reaction mechanism). This three-component coupling reaction represents a useful method for the preparation of stereochemically diverse tertiary alcohols bearing versatile alkenyl and boryl motifs from feedstock 1,3dienes, ketones, and $\mathrm{B}_{2}(\mathrm{pin})_{2}$. The synthetic utility of the reaction was showcased by several transformations.

\section{Conflicts of interest}

There are no conflicts to declare.

\section{Acknowledgements}

J.-J. F. gratefully acknowledges the Alexander von Humboldt Foundation for a postdoctoral fellowship (2017-2020), and Y. X. thanks the China Scholarship Council for a predoctoral fellowship (2018-2022). M. O. is indebted to the Einstein Foundation Berlin for an endowed professorship. Solvias AG is thanked for a generous gift of josiphos ligands.

\section{Notes and references}

1 For reviews of related asymmetric allylation of carbonyl compounds, see: (a) Y.-L. Liu and X.-T. Lin, Adv. Synth. Catal., 2019, 361, 876-918; (b) M. Hatano and K. Ishihara, Synthesis, 2008, 1647-1675; (c) S. E. Denmark and J. Fu, Chem. Rev., 2003, 103, 2763-2793.

2 M. Yus, J. C. González-Gómez and F. Foubelo, Chem. Rev., 2013, 113, 5595-5698.

3 With allylboron reagents: (a) R. Wada, K. Oisaki, M. Kanai and M. Shibasaki, J. Am. Chem. Soc., 2004, 126, 8910-8911; (b) S. Lou, P. N. Moquist and S. E. Schaus, J. Am. Chem. Soc., 2006, 128, 12660-12661; (c) U. Schneider, M. Ueno and S. Kobayashi, J. Am. Chem. Soc., 2008, 130, 1382413825; (d) S.-L. Shi, L.-W. Xu, K. Oisaki, M. Kanai and M. Shibasaki, J. Am. Chem. Soc., 2010, 132, 6638-6639; (e) D. S. Barnett, P. N. Moquist and S. E. Schaus, Angew. Chem., Int. Ed., 2009, 48, 8679-8682; (f) R. Alam, T. Vollgraff, L. Eriksson and K. J. Szabó, J. Am. Chem. Soc., 2015, 137, 11262-11265; (g) D. W. Robbins, K. A. Lee, D. L. Silverio, A. Volkov, S. Torker and A. H. Hoveyda, Angew. Chem., Int. Ed., 2016, 55, 9610-9614; $(h)$ K. A. Lee, D. L. Silverio, S. Torker, D. W. Robbins, F. Haeffner, F. W. van der Mei and A. H. Hoveyda, Nat. Chem., 2016, 8, 768-777; (i) F. W. van der Mei, C. Qin, R. J. Morrison and A. H. Hoveyda, J. Am. Chem. Soc., 2017, 139, 9053-9065.

4 With allylsilicon reagents: (a) S. Yamasaki, K. Fujii, R. Wada, M. Kanai and M. Shibasaki, J. Am. Chem. Soc., 2002, 124, 6536-6537; (b) M. Wadamoto and H. Yamamoto, J. Am. Chem. Soc., 2005, 127, 14556-14557; (c) M. Wadamoto, M. Naodovic and H. Yamamoto, Eur. J. Org. Chem., 2009, 5132-5134.

5 With allyltin reagents: (a) S. Casolari, D. D'Addario and E. Tagliavini, Org. Lett., 1999, 1, 1061-1063; (b) K. M. Waltz, J. Gavenonis and P. J. Walsh, Angew. Chem., 
Int. Ed., 2002, 41, 3697-3600; (c) A. Cunningham and S. Woodward, Synthesis, 2002, 43-44; (d) J. G. Kim, K. M. Waltz, I. F. Garcia, D. Kwiatkowski and P. J. Walsh, J. Am. Chem. Soc., 2004, 126, 12580-12585; (e) Y.-C. Teo, J.-D. Goh and T.-P. Loh, Org. Lett., 2005, 7, 2743-2745; $(f)$ J. G. Kim, E. H. Camp and P. J. Walsh, Org. Lett., 2006, 8, 4413-4416; $(g)$ X. Zhang, D. Chen, X. Liu and X. Feng, J. Org. Chem., 2007, 72, 5227-5233.

6 With allyl halides using a stoichiometric metal reductant: $(a)$ J. J. Miller and M. S. Sigman, J. Am. Chem. Soc., 2007, 129, 2752-2753; (b) X.-R. Huang, C. Chen, G.-H. Lee and S.-M. Peng, Adv. Synth. Catal., 2009, 351, 3089-3095; (c) R.-Y. Chen, A. P. Dhondge, G.-H. Lee and C. Chen, Adv. Synth. Catal., 2015, 357, 961-966; for a review, see: (d) Z.-L. Shen, S.-Y. Wang, Y.-K. Chok, Y.-H. Xu and T.-P. Loh, Chem. Rev., 2013, 113, 271-401.

7 With hydrocarbon pronucleophiles: (a) R. Yazaki, N. Kumagai and M. Shibasaki, J. Am. Chem. Soc., 2009, 131, 3195-3197; (b) R. Yazaki, N. Kumagai and M. Shibasaki, J. Am. Chem. Soc., 2010, 132, 5522-5531; (c) X.-F. Wei, X.-W. Xie, Y. Shimizu and M. Kanai, J. Am. Chem. Soc., 2017, 139, 4647-4650.

8 For authoritative reviews, see: (a) M. Shibasaki and M. Kanai, Chem. Rev., 2008, 108, 2853-2873; (b) C. García and V. S. Martín, Curr. Org. Chem., 2006, 10, 1849-1889.

9 For key reviews, see: (a) S. W. Kim, W. Zhang and M. J. Krische, Acc. Chem. Res., 2017, 50, 2371-2380; (b) K. D. Nguyen, B. Y. Park, T. Luong, H. Sato, V. J. Garza and M. J. Krische, Science, 2016, 354, aah5133; for seminal work on the use of 1,3-dienes as allylmetal equivalents, see: ; $(c)$ F. Shibahara, J. F. Bower and M. J. Krische, J. Am. Chem. Soc., 2008, 130, 6338-6339; (d) E. L. McInturff, E. Yamaguchi and M. J. Krische, J. Am. Chem. Soc., 2012, 134, 20628-20631; (e) J. R. Zbieg, E. Yamaguchi, E. L. McInturff and M. J. Krische, Science, 2012, 336, 324-327.

10 M. Holmes, L. A. Schwartz and M. J. Krische, Chem. Rev., 2018, 118, 6026-6052.

11 For reviews of reductive couplings, see: $(a)$ M. Kimura and Y. Tamaru, Top. Curr. Chem., 2007, 279, 173-207; (b) J. Montgomery, Angew. Chem., Int. Ed., 2004, 43, 3890-3908.

12 Selected examples of reductive couplings of ketones and 1,3dienes. Racemic reactions: (a) Y. Sato, M. Takimoto, K. Hayashi, T. Katsuhara, K. Takagi and M. Mori, J. Am. Chem. Soc., 1994, 116, 9771-9772; (b) M. Kimura, H. Fujimatsu, A. Ezoe, K. Shibata, M. Shimizu, S. Matsumoto and Y. Tamaru, Angew. Chem., Int. Ed., 1999, 38, 397-400; (c) M. Kimura, A. Ezoe, M. Mori, K. Iwata and Y. Tamaru, J. Am. Chem. Soc., 2006, 128, 8559-8568; (d) J. C. Leung, L. M. Geary, T.-Y. Chen, J. R. Zbieg and M. J. Krische, J. Am. Chem. Soc., 2012, 134, 15700-15703; (e) B. Y. Park, T. P. Montgomery, V. J. Garza and M. J. Krische, J. Am. Chem. Soc., 2013, 135, 16320-16323. Asymmetric reactions: (f) Y. Yang, I. B. Perry, G. Lu, P. Liu and S. L. Buchwald, Science, 2016, 353, 144-150; $(g)$ C. Li,
R. Y. Liu, L. T. Jesikiewicz, Y. Yang, P. Liu and S. L. Buchwald, J. Am. Chem. Soc., 2019, 141, 5062-5070.

13 For authoritative reviews of borylative couplings, see: (a) K. Semba and Y. Nakao, Tetrahedron, 2019, 75, 709-719; (b) D. Hemming, R. Fritzemeier, S. A. Westcott, W. L. Santos and P. G. Steel, Chem. Soc. Rev., 2018, 47, 7477-7494; (c) A. P. Pulis, K. Yeung and D. J. Procter, Chem. Sci., 2017, 8, 5240-5247; (d) H. Yoshida, ACS Catal., 2016, 6, 1799-1811; (e) Y. Tsuji and T. Fujihara, Chem. Rec., 2016, 16, 22942313; $(f)$ K. Semba, T. Fujihara, J. Terao and Y. Tsuji, Tetrahedron, 2015, 71, 2183-2197; (g) H. Y. Cho and J. P. Morken, Chem. Soc. Rev., 2014, 43, 4368-4380.

14 H. Y. Cho, Z. Yu and J. P. Morken, Org. Lett., 2011, 13, 52675269.

15 Examples of catalytic asymmetric platinum- and nickelcatalyzed borylative aldehyde-diene couplings: (a) J. B. Morgan and J. P. Morken, Org. Lett., 2003, 5, 25732575; (b) H. E. Burks, L. T. Kliman and J. P. Morken, J. Am. Chem. Soc., 2009, 131, 9134-9135; (c) L. T. Kliman, S. N. Mlynarski, G. E. Ferris and J. P. Morken, Angew. Chem., Int. Ed., 2012, 51, 521-524.

16 Selected examples of enantioselective copper-catalyzed borylative couplings of dienes. With $\alpha, \beta$-unsaturated acceptors: (a) X. Li, F. Meng, S. Torker, Y. Shi and A. H. Hoveyda, Angew. Chem., Int. Ed., 2016, 55, 999710002; with imines: (b) L. Jiang, P. Cao, M. Wang, B. Chen, B. Wang and J. Liao, Angew. Chem., Int. Ed., 2016, 55, 13854-13858; with acylsilanes: (c) J.-J. Feng and M. Oestreich, Angew. Chem., Int. Ed., 2019, 58, 8211-8215; with electrophilic cyanating reagents: (d) T. Jia, M. J. Smith, A. P. Pulis, G. J. P. Perry and D. J. Procter, ACS Catal., 2019, 9, 6744-6750; with aryl halides: (e) S. R. Sardini and M. K. Brown, J. Am. Chem. Soc., 2017, 139, 9823-9826; (f) K. B. Smith, Y. Huang and M. K. Brown, Angew. Chem., Int. Ed., 2018, 57, 6146-6149.

17 Selected examples of copper-catalyzed borylative couplings with carbonyl compounds. Intermolecular: (a) F. Meng, H. Jang, B. Jung and A. H. Hoveyda, Angew. Chem., Int. Ed., 2013, 52, 5046-5051; (b) F. Meng, F. Haeffner and A. H. Hoveyda, J. Am. Chem. Soc., 2014, 136, 11304-11307; (c) S. Gao and M. Chen, Chem. Sci., 2019, 10, 7554-7560; (d) X.-C. Gan and L. Yin, Org. Lett., 2019, 21, 931-936; intramolecular: (e) A. R. Burns, J. S. González and H. W. Lam, Angew. Chem., Int. Ed., 2012, 51, 10827-10831; (f) Y.-S. Zhao, X.-Q. Tang, J.-C. Tao, P. Tian and G.-Q. Lin, Org. Biomol. Chem., 2016, 14, 4400-4404; $(g)$ E. Yamamoto, R. Kojima, K. Kubota and H. Ito, Synlett, 2016, 27, 272-276.

18 For reports on the synthesis of chiral compounds by carbonyl (hydroxymethyl)allylations with antidiastereoselectivity, see: (a) Y. J. Zhang, J. H. Yang, S. H. Kim and M. J. Krische, J. Am. Chem. Soc., 2010, 132, 4562-4563; (b) J. Feng, V. J. Garza and M. J. Krische, J. Am. Chem. Soc., 2014, 136, 8911-8914. 